Coletânea: O que é isso, pai, é outra na cidade de Bissau?

Jorge Otinta ${ }^{1}$

\title{
HEIDEGGER GIGI
}

Dispus di jubi si fiju na fundu di si ujus, i sai ku es:

Olhando no fundo dos olhos do próprio filho, diz-lhe o pai:

Psikosomatiku

Psicossomático

(Fiju rabida i jubi papé... i pensa ku si kabesa di mininu ku sibi ciu; nos tan i ciu ki ta skirbidu?)

(O filho fitou ao pai. Pensando na sua sabedoria de menino astuto)

- Es mas i kê? Papa kê i utru nubdadi más na Bissau?

- O que é isso, pai, é outra na cidade de Bissau?)

(I ruspundil ku dintis murdidus di raiba)

(Rangendo os dentes, respondeu-lhe, com certa ira)

- Na nundé?

- Onde?

(Sin koragen di torna fala pa si papé, i sai tan ku és). Ker ser: kada kin ku disel:

(A tremer dum medo friorento, devolveu ao pai, dizendo-o que cada um tinha os seus problemas)

- Anta, papé di mi, ñu disal pon na psikomesusadu...

(E arrematou: Então, pai, é melhor deixar isto como psicossubtraído)

15 Jan. 2012.

\footnotetext{
1 Jorge Otinta, tradutor e poeta. Doutor em Letras (Estudos Comparados de Literaturas de Língua Portuguesa) pela FFLCH/USP.
} 


\section{NOVO CEMITÉRIO}

Ospital, si ñu na rapada,

Veja, se reparares bem, o hospital

i sedu nan gosi

transformou-se agora

siminteru di almas bibus

no cemitério dos vivos, ora!

12 Fev. 2012. 


\section{DISSOLUÇÃO}

O homem

se esforça

se multiplica,

se autocria escrupulosamente

nas deslocações imaginativas

para a solução do problema fundamental:

restringir-se

a uma negação absoluta.

Uma força

proporcional

o coloca à deriva

Ele, como se fosse uma fantasia,

ou um capricho dissolvente

de um destino mofino.

Apesar do que tenho visto

e imaginado

e pensado

e sentido

e vivido

imagino a minha Bissau

que me mete medo

à vista,

pois, quando a cidade cala

o país chora

Doismilenove

num áspero março estrondoso,

pecaminoso

a seguir-lhe

junho criminoso

abrem-se, em mim, os arsenais

da discórdia

que me conduz

ao rés-do-chão

da história menina

que, sem começar, termina

na chuva de sangue fina. 


\author{
Meus olhos \\ ávidos de utopias \\ contradizem-se \\ com meus dias ácidos \\ de tensas ventanias \\ e de últimas recordações \\ que o Cais (não) esquece \\ imolações, \\ frustrações \\ lamentos de minha perdição \\ não fosse a teimosa fé \\ na singidura feição \\ do meu lopé 2 .
}

\author{
Algumas kassabis ${ }^{3}$ sme perseguem \\ e, paralelamente, algumas saburas ${ }^{45}$ persistem \\ muitas léguas \\ a atravessar \\ quiçá, um dia de ternura \\ há-de vir \\ se o sonho \\ assim o convir.
}

Bissau/Março/2009

${ }^{2}$ Singidura di lopé, no kriol guineense, significa o nó do pano tradicional usado na cintura pelos homens da tabanka (aldeia).

${ }^{3}$ Singidura di lopé, no kriol guineense, significa o nó do pano tradicional usado na cintura pelos homens da tabanka (aldeia).

${ }^{4}$ Também do kriol, prazeroso, gostoso, o que dá sorte e graça.

${ }^{5}$ Também do kriol, prazeroso, gostoso, o que dá sorte e graça. 


\title{
SABIS \& KASSABIS 67
}

\author{
Ruas de utopias \\ a encarar problemas sérios \\ ruas de sangue \\ a zangar-se da coragem \\ de sempre perder \\ e o homem \\ como se fosse uma máscara \\ diante do espelho
}

E a companhia silenciosa

dum disfarce

que mistura verdades

e mentiras

cujos amores

debruçam-se em jogos de mentiras

fingidas

em que os sujeitos matam-se

de torturas

nas casas vazias

duma tarde sombria

Mais covarde do que tu, Tita $\mathrm{N} \mathrm{Ti}^{8}$,

somente

a minha sombra-disfarce

que encostou suas mãos

às minhas costas

comendo

às minhas custas

e, assim, sem jeito, beijo a luz

que doira a cidade

empoeirada

de horas a fio

em pensamentos vãos

à espera de kuntango ${ }^{9}$

ou à espera do siti ku liti

da (minha) mãe-avó

cujo cheiro

atravessa a minha narina

${ }^{6}$ Graças e desgraças.

${ }^{7}$ Graças e desgraças.

${ }^{8} \mathrm{~N}$ Ti é o nome que os antigos davam à cidade de Bissau. Significa a coisa/patrimônio de que se dispõe. Que dizer "Eu tenho" ou "Eu possuo". Trata-se da relação de possessão, de pertença em relação à cidade de Bissau.

${ }^{9}$ Kuntango, comida feita a água e sal sem nenhum outro ingrediente ou mafé (molho). 
como a rusga da pop

da segunda esquadra

$\mathrm{Na}$ alquimia

das minhas cé(d)lulas

de cidadão

ventos que se movem

em direção ao cais

braços de outros transeuentes

que se erguem

entre cajueiros

e mangueiras

e acácias

e prédios coloniais

que trazem para mim,

a partir de fora,

um pouco do sol

da rua

e as águas do Geba

cheiram à suco de veludo

e cabaceira

como se estivem

a leme

e eu à proa

com o barco

ao largo

em direção às ilhas

no incendiar do sol

que exibe o riso

da menina do mar,

a sereia malgosada 10 !

Não deito fora

as flores

na ondulante maré

do cais,

porque as palavras

que balbuciarei

serão apenas cadáveres

só de palavras

nem aos mortos de 59

nem aos de 63

e nem aos de 98

com os abraços

e afagos

${ }^{10}$ Malgosada, sacralizada, sagrada. 
rumorosos da vida

das munições civilizacionais

esgotadas do tuga

que chama

nossos grandes

de turras do engenheiro

nessa nova lava

de onda

de dinheiro

que subtraem

do erário

frustrando

o peso

da tua alegria

causando-te pesares

de tantas madrugadas acordadas, comandante!

Insônias?!

só insônias,

um gosto necrófilo

de lágrima furtiva

como furtiva

é o nosso instante

de sorrir

de ir

e de vir

em entidades

irans daqui

e deuses dacolá

na lisura

das significâncias

que enxertamos em nós

num ódio generoso,

cordial, e, sempre, cínico

do vácuo

do destino atroz

qual o mistério

da caverna

cavernada na Baiana

por causa das mortes

rotineiras

feitas

de seculares injustiças

como se procedêssemos

ao ritual diário

de negras formigas 


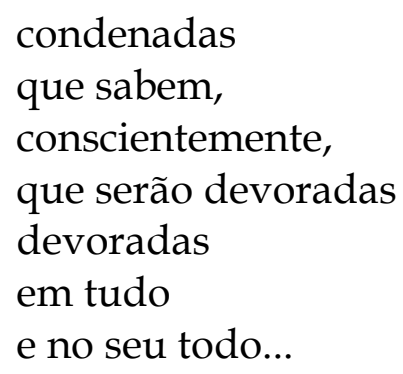

A época

lá se foi,

mas a memória

permanece viva

na mesma mentalidade

assoberbada,

assombrando-nos,

penosamente.

O resto

pertence a Ampa ${ }^{11}$

julgar

já que a História

não o faz

nesta gólgota pessoal

a que estamos mergulhados

nesta via sacra sexual

que nos assola, viciosamente, como o calvário

duma servidão férrea

indeterminada

pelos de fora

como se N Dingui ${ }^{12}$ nos chamássemos

ou kikia ${ }^{13}$ nos denominássemos

a fotografia

do nosso passado

que se presentifica

futurologicamente

nas paredes

de nossas mentes

nuas

a estragar

o nosso ser:

tu, eu e ele!

${ }^{11}$ Refiro-me, em homenagem, ao poeta guineense Jorge Ampa Cumelerbo.

${ }^{12} \mathrm{~N}$ Dingui, o solitário. Retomo uma personagem do Kikia Matcho, romance do escritor guineense Filinto de Barros.

${ }^{13}$ Kikia, coruja ou mocho. 
Na concreta morte

anunciada de sonhos

dentro do silêncio

roído

na memória

do tempo

e no corpo

do espaço

como numa teia

de nervuras

do real

do devir

do respirar

do silêncio nosso,

sendo-nos, simultaneamente, pós

e plânctons pensantes

sentiendis,

operandis

e faciendis,

essendis, enfim...

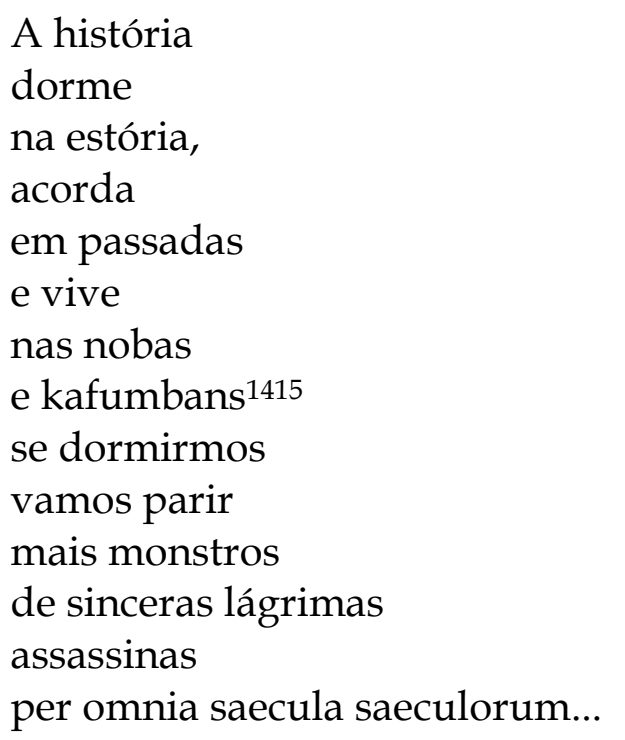

Assim, eu rio

o rio

sorrio

para ele

no frio

de suas margens

um sorriso

sobre suas águas

${ }^{14}$ Notícias e boatos.

15 Notícias e boatos. 


\author{
que, sem parar, \\ desaguam em ti, \\ Tita N Ti! \\ O mar \\ é o útero \\ da terra \\ com suas parcas \\ linhas \\ humanas \\ Nossa Senhora \\ de San Bacil \\ protegei-nos! \\ Faça-nos \\ dar \\ saltos \\ da morte \\ para \\ os ovários \\ da vida, \\ nós, os teus filhos, \\ $n$ djeñerus \\ e $n$ djeñadus ${ }^{1617 !}$ \\ As algas \\ do Geba, \\ protegei \\ esta terra \\ N Ti!
}

São Paulo/Junho/2011

\footnotetext{
${ }^{16} \mathrm{~N}$ djeñerus e n djeñadus (são as pessoas que levam a vida ao Deus dará). Ou a mercê da sorte dos outros.

${ }^{17} \mathrm{~N}$ djeñerus e $\mathrm{n}$ djeñadus (são as pessoas que levam a vida ao Deus dará).
} 


\section{AI, POR FAVOR, NÃO CAI}

Da sombra de uma ponte em construção

Descem lentamente

As chamas sombrias de uma manhã orvalhada de concretos. 